\title{
Extraction Optimization and Antioxidant Properties of African Eggplant (Solanum macrocarpon) Leaf Polyphenols
}

\author{
A. A. Famuwagun, ${ }^{1}$ K. A. Taiwo, ${ }^{1}$ S. O. Gbadamosi, ${ }^{1}$ D. J. Oyedele, ${ }^{2}$ \\ R. E. Aluko, ${ }^{3}$ and O. C. Adebooye ${ }^{4}$ \\ ${ }^{1}$ Department of Food Science and Technology, Faculty of Technology, Obafemi Awolowo University, Ile-Ife, Nigeria \\ ${ }^{2}$ Department of Soil and Land Resources Management, Faculty of Agriculture, Obafemi Awolowo University, Ile-Ife, Nigeria \\ ${ }^{3}$ Department of Human Nutritional Sciences, University of Manitoba, Winnipeg, MB, Canada R3T 2N2 \\ ${ }^{4}$ Department of Agronomy, Osun State University, Osogbo, Nigeria
}

Correspondence should be addressed to A. A. Famuwagun; akinsolaalbert@gmail.com

Received 15 July 2017; Revised 29 September 2017; Accepted 6 November 2017; Published 29 November 2017

Academic Editor: Riccarda Antiochia

Copyright (C) 2017 A. A. Famuwagun et al. This is an open access article distributed under the Creative Commons Attribution License, which permits unrestricted use, distribution, and reproduction in any medium, provided the original work is properly cited.

\begin{abstract}
Optimization of the yield, total phenolic content (TPC), and total antioxidant activities (TAA) of polyphenol concentrates extracted from Solanum macrocarpon leaves was studied using response surface methodology. The process variables investigated included extraction temperature $\left(30,50\right.$, and $\left.70^{\circ} \mathrm{C}\right)$, extraction time $(2,4$, and $6 \mathrm{~h})$, and dried leaf powder: water ratio $(1: 10,1: 20$, and $1: 30 \mathrm{w} / \mathrm{v})$. Box-Behnken design resulted in 15 experimental runs. The results showed the following optimum extraction conditions: temperature, $49.05^{\circ} \mathrm{C}$; extraction time, $243 \mathrm{~min}$; leaf powder: water ratio, $1: 22 \mathrm{w} / \mathrm{v}$. The optimized extraction conditions gave polyphenol concentrate yield, TPC, and TAA values of $24.94 \%, 421.09 \mathrm{mg} \mathrm{GAE} / \mathrm{g}$, and $23.81 \mathrm{mg}$ AAE/g, respectively. Results of the in vitro antioxidant activities of the polyphenol concentrate showed 2,2-diphenyl-2-picrylhydrazyl hydrate, metal chelating ability, and ferric reducing ability values of $76.78 \%, 80.22 \%$, and $56.46 \mathrm{mg} \mathrm{AAE} / \mathrm{g}$, respectively. The study concludes that the experimental values compared closely with the predicted values, which indicates suitability of the model employed for polyphenol extraction optimization from dried S. macrocarpon leaves.
\end{abstract}

\section{Introduction}

Solanum macrocarpon otherwise known as the African eggplant is a tropical perennial plant of the Solanaceae family. The part of the plant that is consumed is the fruits and its young leaves. The roots, leaves, and fruit of $S$. macrocarpon have been reported to have some medicinal food potentials. In Nigeria, the fruit is used as a laxative and used for the treatment of cardiac diseases [1]. S. macrocarpon leaves, a widespread plant genus of the family Solanaceae, has over 1000 species worldwide and at least 100 indigenous species in Africa and adjacent Islands [2]. The use of S. macrocarpon in indigenous medicine ranges from weight reduction to treatment of several ailments including asthma, allergic rhinitis, nasal catarrh, skin infections, rheumatic disease and swollen joint pains, gastroesophageal reflux disease, constipation, and dyspepsia [3]. Locally, the leaves constitute an important part of the diet because they are considered to be of high nutritional value and, therefore, used in the preparation of soups and stews. The leaves are rich in protein, fat, crude fibre, calcium, and zinc [1] and are found to contain appreciable amounts of the sulphur-containing amino acid methionine $[4,5]$.

Several research results have revealed anti-inflammatory, antiasthmatic, antiglaucoma, hypoglycemic, hypolipidemic, and weight reduction effects of this green leafy vegetable $[1,5$, 6]. These pharmacological properties have been attributed to the presence of certain chemical substances in the plants, such as polyphenols [7]. Phytochemical studies of S. macrocarpon leaves showed that the leaves contained appreciable quantities of polyphenols, especially the flavonoids [5], which could contribute to strong antioxidant properties.

The need for health consciousness of consumers has led to increase in the demand for natural antioxidants that improve 
TABLE 1: Extraction factors and their levels for Box-Behnken design.

\begin{tabular}{|c|c|c|c|c|}
\hline \multirow{2}{*}{ Variables } & \multirow{2}{*}{ Code } & \multicolumn{3}{|c|}{ Range and level } \\
\hline & & -1 & 0 & +1 \\
\hline Temperature $\left({ }^{\circ} \mathrm{C}\right)$ & $A$ & 30 & 50 & 70 \\
\hline Time (h) & $B$ & 2 & 4 & 6 \\
\hline Ratio of powder to water $(\mathrm{w} / \mathrm{v})$ & C & $1: 10$ & $1: 20$ & $1: 30$ \\
\hline
\end{tabular}

the nutritional quality of food products. Food industries are meeting the demand for antioxidants through the use of compounds such as polyphenols that are extracted from natural sources [8]. When present in foods, dietary antioxidants can quench free radicals and inhibit lipid peroxidation, which prevents nutritional and quality deterioration. Although, synthetic antioxidants like butylated hydroxytoluene, butylated hydroxyanisole, and propyl gallate are common food additives that promote shelf life, their use has been questioned due to potential toxicity and carcinogenic effects. Therefore, the need for natural antioxidants is rapidly increasing in the food industry [5].

The extraction of bioactive compounds from plant materials is the first step in the utilization of phytochemicals as ingredients for the preparation of dietary supplements and formulation of food products [9]. Phenolics present in plant materials can be extracted using various organic solvents such as methanol, ethanol, acetone, and ethyl acetate or their combinations with different proportions of water [10]. The extraction of phenolic compounds and antioxidant activities of aqueous extract of $S$. macrocarpon leaves have been reported to be affected by many factors including the ratio of solid to solvent, the extraction times, and temperature. Under this situation where multiple variables influence the output, response surface methodology (RSM) is a suitable technique for optimizing the process [11]. RSM is a method for designing statistical experiments, modelling the processes, and verifying the statistical significance of independent variables and is used to obtain the optimum operating conditions of the entire process [12]

Therefore, the main objective of the present work was to optimize the extraction conditions including solventsample ratio, temperature, and extraction time for maximizing polyphenol concentrate production from $S$. macrocarpon leaves using response surface methodology. Antioxidant properties of the polyphenol concentrates were also determined to establish potential uses as food preservatives and health-promoting agents.

\section{Materials and Methods}

2.1. Materials. Fresh S. macrocarpon leaves were obtained from the Teaching and Research Farm of Obafemi Awolowo University, Ile-Ife, Osun State, Nigeria. Botanical authenticity of the vegetable leaves was done by the Botany Department of the Obafemi Awolowo University and was deposited at the herbarium with voucher number SLM/BOT/234089 for reference. All chemicals for the analysis were of analytical grade and were purchased from Aldrich-Sigma Inc., Germany.
2.2. Preparation of Eggplant Leaf Powder. The fresh eggplant leaves were destalked, rinsed with clean water, cut into small pieces, and dried in a hot air oven (Uniscope SM 9053 Laboratory Oven Surgifield Medicals, England) at $60^{\circ} \mathrm{C}$ for $8 \mathrm{~h}$. The dried leaves were then milled into powder using a laboratory blender (Sapphire mixer grinder, 3642964, India). The milled powder was later passed through a laboratory sieve of mesh size 315 microns (Laboratory Test Sieve, Endecotts, limited, IS033-10, London, England) and packaged in an air-tight container until required for extraction.

\subsection{Experimental Design of Polyphenol Concentrates Extrac-} tion. In the present study, a Box-Behnken experimental design was employed in the extraction of polyphenol concentrates from eggplant leaf powder. Three level-three factors which generated fifteen (15) experimental runs were employed. These experimental runs included 9 factorial points, 3 axial points, and 3 central points. This was done to provide opportunity for the estimation of a pure error, sum of squares, and interiors of the experimental regions. The variables selected for the extraction of polyphenol concentrates were temperature $(A)$, time $(B)$, and leaf powder : water ratio $(C)$. The coded levels for the independent variables are shown in Table 1. Randomized experiments were carefully employed to reduce the effect of external factors on the observed responses.

\subsection{Aqueous Extraction of Polyphenol Concentrates from} Eggplant Leaf Powder. Ten grams $(10 \mathrm{~g})$ of eggplant leaf powder was dispersed in 100,200, and $300 \mathrm{ml}$ of preheated water (to the desired temperature) at different times in a $1 \mathrm{~L}$ glass beaker to form a suspension. This resulted in different solid to water ratios of $1: 10,1: 20$, and $1: 30 \mathrm{w} / \mathrm{v}$. The glass beakers containing the suspension were placed on a thermostatic magnetic stirrer for extraction. During this period, the temperature of the suspension in the glass beakers was thermostatically regulated while stirring for the desired length of times. The suspensions were later centrifuged at $3500 \times \mathrm{g}$ for $30 \mathrm{~min}$ to obtain clear filtrates. The filtrates were concentrated using a rotary evaporator (Rotary Evaporator RE-52A, Union Laboratories, England) at $50^{\circ} \mathrm{C}$. The concentrates were poured in a preweight vacuum plate and dried in a vacuum oven (Shell Lab, ILMAC Vacuum Oven) at a pressure of $100 \mathrm{mBar}$ for $12 \mathrm{~h}$. The final products obtained were the polyphenol concentrates and the yields were calculated as percentage of the starting material as described in equation (1) 
Polyphenol concentrates yield $\%(w / w)=\frac{\text { final weight of the vaccum plate }- \text { initial weight of vaccum plate }}{\text { weight of the starting material }} \times 100$

2.5. Determination of Total Phenolic Content (TPC) of the Polyphenol Concentrate. The determination of the total phenolic content of the extract was carried out using FolinCiocalteu's phenol reagent as described by Singleton and Rossi [13]. The calibration curve solutions were prepared by pipetting $0.0,0.2,0.4,0.6,0.8$, and $1.0 \mathrm{~mL}$ of gallic acid standard solution $(1.0 \mathrm{mg} / \mathrm{mL}$ gallic acid) in triplicate into clean dried test tubes. The samples were prepared as $1 \mathrm{mg} / \mathrm{mL}$ dispersions in distilled water. From the bulk preparation, $0.2 \mathrm{~mL}$ each of $1 \mathrm{mg} / \mathrm{mL}$ solution was pipetted into clean dry test tubes in triplicate. Each test tube (containing standard and samples) was made up to $1.0 \mathrm{~mL}$ with distilled water. To each of the test tube was added $1.5 \mathrm{~mL}$ of diluted $(1: 4 \mathrm{v} / \mathrm{v})$ Folin-Ciocalteu's reagent. The mixture was incubated at room temperature for $5 \mathrm{~min}$ followed by the addition of $1.5 \mathrm{~mL}$ of $10 \%(\mathrm{w} / \mathrm{v}) \mathrm{NaHCO}_{3}$ solution to give a total volume of $4.0 \mathrm{~mL}$. The reaction mixtures were further incubated for additional $90 \mathrm{~min}$ and the absorbance was read at $725 \mathrm{~nm}$ in a spectrophotometer (INESA, 752N UV-VIS Spectrophotometer) against a blank that contained all reagents except the standard gallic acid which was replaced with distilled water. The standard curve was obtained by plotting absorbance against the concentration of each diluted gallic acid solution. The concentrations of the phenolic compounds in the extract were extrapolated from standard curve as shown in Figure 1 and expressed as mg gallic acid equivalent per $\mathrm{g}(\mathrm{mg} \mathrm{GAE} / \mathrm{g}$ ) taking into consideration the dilution factor of the samples. The initial value extrapolated from the standard curve gave the concentration in $\mu \mathrm{gGAE} / \mathrm{mL}$. The concentration in $\mathrm{mg}$ GAE/g extract was obtained using

$$
\mathrm{TPC}(\mathrm{mgGAE} / \mathrm{g})=\frac{\mu \mathrm{gGAE} \times 1 \mathrm{mg} \times \mathrm{mL} \text { of solvent used in dissolving the sample } \times \text { dilution factor }}{\mathrm{mL} \times 1000 \mu \mathrm{g} \times \text { mass of the sample used }}
$$

2.6. Determination of Total Antioxidant Activity (TAA). The total antioxidant activity (TAA) of the extract was determined according to the method described by Prieto et al. [14] and expressed as mg ascorbic acid equivalents (AAE)/g of dried leaf powder. The calibration curve solutions were prepared by pipetting $0.0,20.0,40.0,60.0,80.0$, and $100.0 \mu \mathrm{g} / \mathrm{mL}$ of ascorbic acid standard solution in triplicate into clean dried test tubes. The samples for the analysis were prepared as 1 $\mathrm{mg} / \mathrm{mL}$ solutions in distilled water. From the standard and sample solutions prepared, $100 \mu \mathrm{L}$ of each was pipetted into separate test tubes and made up to $1.0 \mathrm{~mL}$ with distilled water. One $\mathrm{mL}(1.0 \mathrm{~mL})$ of the reagent (consisting of $28 \mathrm{mM}$ trisodium phosphate and $4 \mathrm{mM}$ ammonium molybdate in
$100 \mathrm{~mL}$ standard flask and made up to the mark with $0.6 \mathrm{M}$ sulphuric acid) was added to each standard, extract, and blank (prepared by replacing extract with distilled water). The test tubes were capped, incubated at $100^{\circ} \mathrm{C}$ for $90 \mathrm{~min}$, and cooled to room temperature, and absorbance of the reaction mixtures was then measured at $695 \mathrm{~nm}$ against a reagent blank in a spectrophotometer (INESA, 752N UVVIS). Ascorbic acid calibration curve was obtained by plotting absorbance of the diluted standard solutions against concentration and TAA (mg AAE/g extract) obtained from the curve by extrapolation. The value extrapolated from the standard curve gave the concentration in $\mu \mathrm{g} \mathrm{AAE} / \mathrm{mL}$. The concentration in mg AAE/g extract was obtained using

$$
\operatorname{TAA}\left(\frac{\mathrm{mgAAE}}{\mathrm{g}}\right)=\frac{\mu \mathrm{gAAE} \times 1 \mathrm{mg} \times \mathrm{mL} \text { of solvent used in dissolving the sample } \times \text { dilution factor }}{\mathrm{mL} \times 1000 \mu \mathrm{g} \times \text { mass of the sample used }}
$$

\subsection{Antioxidant Properties of the Polyphenol Concentrates}

2.7.1. 2, 2-Diphenyl-2-picrylhydrazyl Hydrate (DPPH) Assay. The radical scavenging ability of the extracts was determined using the stable radical DPPH as described by Pownall et al. [15].

The calibration curve of the standard solution was prepared by pipetting $0.0,0.2,0.4,0.6,0.8$, and $1.0 \mathrm{~mL}$ of ascorbic acid standard solution $(1.0 \mathrm{mg} / \mathrm{mL}$ ascorbic acid) in triplicate into clean dried test tubes and made up to $1 \mathrm{~mL}$ with distilled water. Different concentrations of the extract were prepared by pipetting $0.0,0.2,0.4,0.6,0.8$, and $1.0 \mathrm{~mL}$ of a $200 \mu \mathrm{g} / \mathrm{mL}$ solution into clean dried test tubes and made up to $1 \mathrm{~mL}$ with distilled water. To $1 \mathrm{~mL}$ of the diluted extract and standard ascorbic acid solutions, $1 \mathrm{~mL}$ of $0.3 \mathrm{mM} \mathrm{DPPH}$ in methanol was added. The mixture was incubated in the dark for $30 \mathrm{~min}$ and the change in colour from deep violet to light yellow was measured spectrophotometrically (INESA, 752N UVVIS Spectrophotometer) at $517 \mathrm{~nm}$ against a DPPH control containing only $1 \mathrm{~mL}$ methanol in place of the extracts.

The percentage of inhibition was calculated in the following way: 


$$
\text { Inhibition (\%) } \frac{A_{\text {control }}-A_{\text {sample }}}{A_{\text {control }}} \times 100,
$$

where $A_{\text {control }}$ is the absorbance of the control reaction (containing all reagents except the test compound) and $A_{\text {sample }}$ is the absorbance of the test compound. Inhibition concentration leading to $50 \%$ inhibition of the free radical $\left(\mathrm{IC}_{50}\right)$ by the extracts was calculated from the graph by plotting inhibition percentage against extract concentrations and compared with the $\mathrm{IC}_{50}$ value of ascorbic acid.

2.7.2. Ferric Reducing Antioxidant Power (FRAP). The ferric reducing antioxidant power (FRAP) assay was carried out according to the method of Benzie and Strain [16]. A $300 \mathrm{mM}$ acetate buffer, pH 3.6, was mixed with $10 \mathrm{mM} \mathrm{2,} \mathrm{4,} \mathrm{6-tris} \mathrm{(2-}$ pyridyl)-1,3,5- triazine and $20 \mathrm{mM}$ ferric chloride in the ratio of $10: 1: 1$, respectively, to give the working FRAP reagent. Ascorbic acid calibrated solutions (0.0, 20.0, 40.0, 60.0, 80.0, and $100.0 \mu \mathrm{g} / \mathrm{mL}$ ) were prepared and $50 \mu \mathrm{L}$ of each was pipetted into separate text tubes. Two hundred microlitres $(200 \mu \mathrm{L})$ of a $1 \mathrm{mg} / \mathrm{mL}$ aqueous extract solution was pipetted into clean test tubes and made up to $1 \mathrm{~mL}$ with distilled water; $50 \mu \mathrm{L}$ of the diluted extract solution was pipetted into another set of clean and dried test tubes. FRAP reagent $(1.0 \mathrm{~mL})$ was added to the standards, extract, and blank (prepared by replacing extract with distilled water). The solution was mixed together and incubated for $10 \mathrm{~min}$. The absorbance of each solution was taken at $593 \mathrm{~nm}$ in a spectrophotometer (INESA, 752N UV-VIS Spectrophotometer) and the ascorbic acid calibration curve was obtained by plotting absorbance of the standard solutions against concentration. The FRAP values of the extracts were obtained from the ascorbic acid standard curve by extrapolation. FRAP was expressed as $\mu \mathrm{g}$ $\mathrm{AAE} / \mathrm{g}$ extract.

2.7.3. Metal Chelating Ability Assay. The metal chelating assay was carried out according to the method of Singh and Rajini [17]. A $1 \mathrm{~mL}$ solution each of $2 \mathrm{mM} \mathrm{FeCl}_{2} \cdot 4 \mathrm{H}_{2} \mathrm{O}$ and $5 \mathrm{mM}$ ferrozine was separately diluted to $20 \mathrm{~mL}$ with distilled water. Ethylene diamine tetra acetic acid (EDTA) calibration curve and polyphenol extract solutions were prepared as $6.25,12.50,25.00,50.00$, and $100.0 \mathrm{mg} / \mathrm{mL}$ concentrations. To the prepared extracts and standard solutions was added $1 \mathrm{~mL} \mathrm{FeCl} 2 \cdot 4 \mathrm{H}_{2} \mathrm{O}$; after a $5 \mathrm{~min}$ incubation, the reaction was initiated by the addition of $1 \mathrm{~mL}$ ferrozine. The mixture was shaken and after a further $10 \mathrm{~min}$ incubation period, the absorbance of the solution was measured spectrophotometrically (INESA, 752N UV-VIS Spectrophotometer) at $562 \mathrm{~nm}$. The percentage inhibition of ferrozine $-\mathrm{Fe}^{+2}$ complex formations was calculated using

$$
\text { Chelating effect }=\frac{A_{\text {control }}-A_{\text {sample }}}{A_{\text {control }}} \times 100,
$$

where $A_{\text {control }}$ is the absorbance of control sample (the control contained $1 \mathrm{~mL}$ each of $\mathrm{FeCl}_{2}$ and ferrozine, complex formation molecules) and $A_{\text {sample }}$ is the absorbance of extracts. Sample concentration leading to $50 \%$ chelation $\left(\mathrm{IC}_{50}\right)$ was calculated from the graph by plotting inhibition percentage against extract concentrations and compared with the $\mathrm{IC}_{50}$ of EDTA.

2.8. Statistical Analysis. The data obtained were analyzed using response surface methodology to fit the quadratic polynomial equation generated by the Design Expert software version 7.0.3.1 (Stat-Ease Inc., Minneapolis, MN, USA). The quality of the fit of the model was evaluated using a test of significance and analysis of variance (ANOVA). The fitted quadratic response model in the present study is described by

$$
Y_{i}=\beta_{0}+\sum_{j=1}^{k} \beta j X j+\sum_{j=1}^{k} \beta j j X j j+\sum \sum_{i>j=1}^{k} \beta i j X i X j+e,
$$

where " $Y$ " is the response variable, $\beta_{0}$ is the intercept value, $\beta i(i=1,2, \ldots, k)$ is the first-order model coefficient, $\beta i j$ is the interaction effect, $\beta i i$ represents the quadratic coefficients of $X i$, and $e$ is the random error.

\section{Results and Discussion}

3.1. Optimization of Polyphenol Concentrate Extraction from Eggplant Leaves. Table 2 shows the factors for the extraction and the experimental and predicted values of the responses measured in the present study. The test of significance for the regression coefficient for the responses, which includes the sum of squares, mean squares, the degree of freedom, the $F$ value, and $p$ values, is presented in Table 3 . The results showed that the probability values of the model for all the responses evaluated were significant $(p<0.05)$ as shown in Table 4 . In the present study, all the three linear terms ( $A, B, C)$ were found to be significant on the yield of polyphenol concentrates and two interaction terms were also found to be significant $(A B$ and $B C)$. On total phenolic content, one linear term $(A)$, one interaction term $(B C)$, and all the three quadratic terms $\left(A^{2}, B^{2}, C^{2}\right)$ were observed to be significant. Furthermore, two linear terms $(A, C)$ and all the quadratic terms $\left(A^{2}, B^{2}, C^{2}\right)$ were significant model terms at 0.95 confidence interval on the TAA of polyphenol concentrates. The $F$ values and corresponding probability values can also be used to evaluate the level of significance of process conditions.

The larger the $F$ values, the stronger the significance of a factor on the process condition [18, 19]. Based on the high $F$ value and low probability value, the decreasing order of significance of the selected factors is as follows: temperature $A>$ leaf powder: water ratio $B>$ time $C$; temperature $A>$ time $B>$ vegetable powder: water ratio $C$; temperature $A>$ leaf powder : water ratio $C>\operatorname{time} B$, respectively, on the yield, TPC, and TAA of the polyphenol concentrates (Table 3).

Table 4 showed the analysis of variance (ANOVA) for the regression equations. The results showed that the models for all the responses were significant $(p<0.05)$. The coefficients of multiple determinations $\left(R^{2}\right)$ for the responses of the yield of the polyphenol concentrates, the TPC, and the TAA were $0.967,0.986$, and 0.980 , respectively. This result showed that the model was able to explain $96.7 \%, 98.6 \%$, and $98.0 \%$ of the 


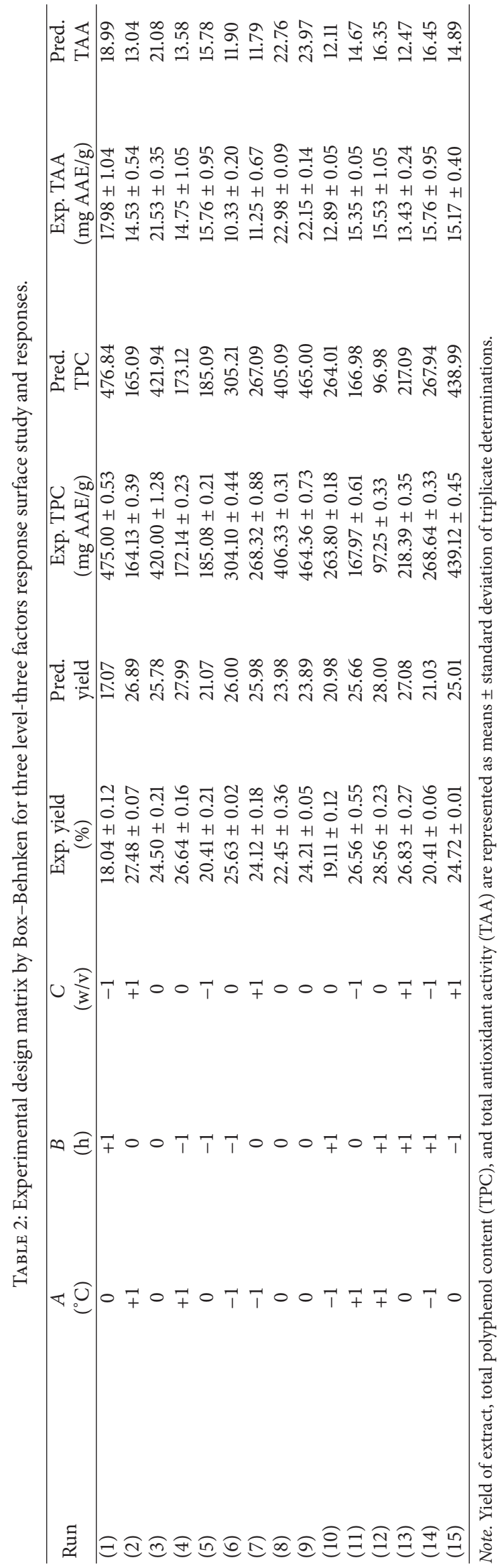




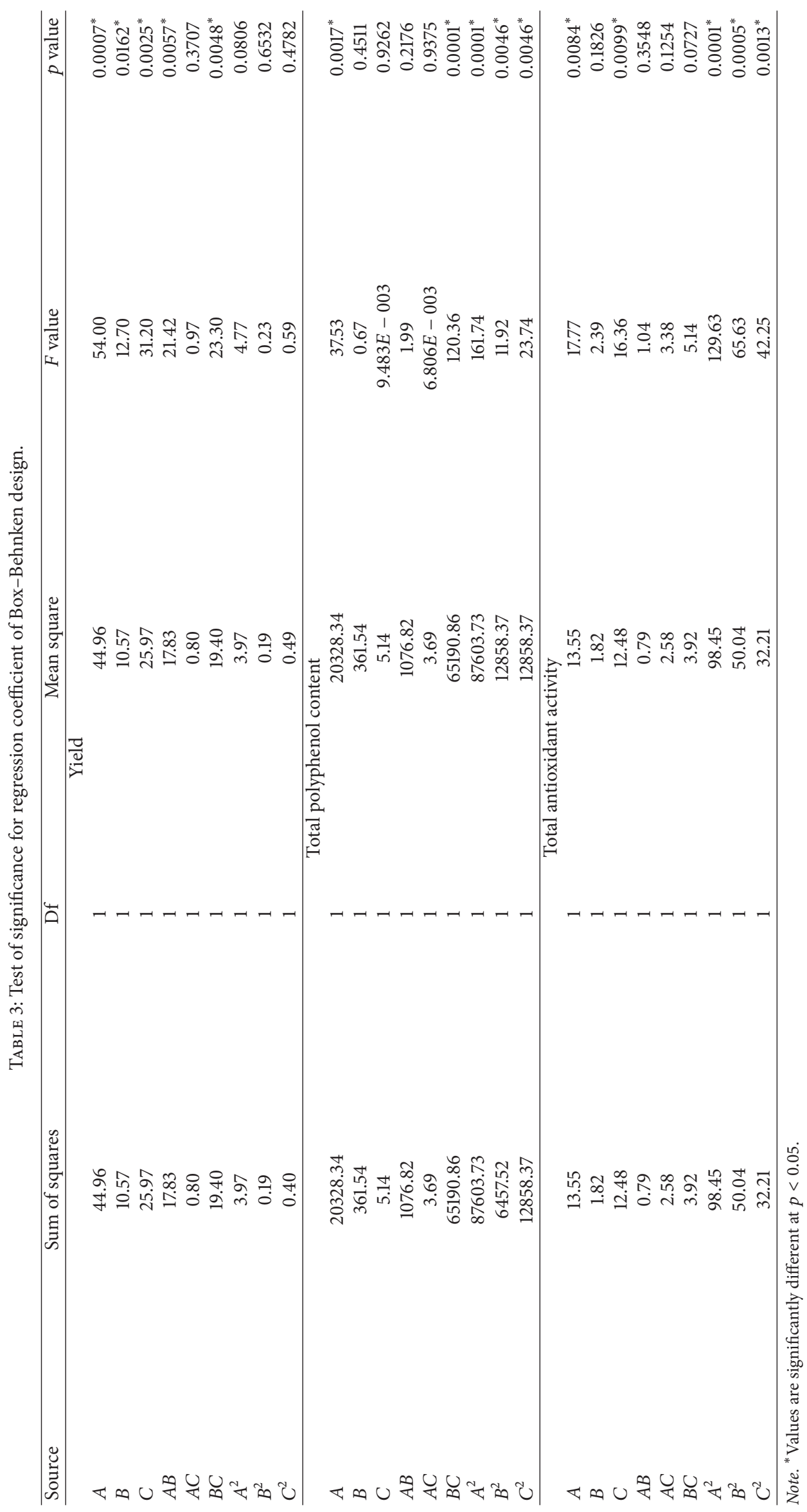




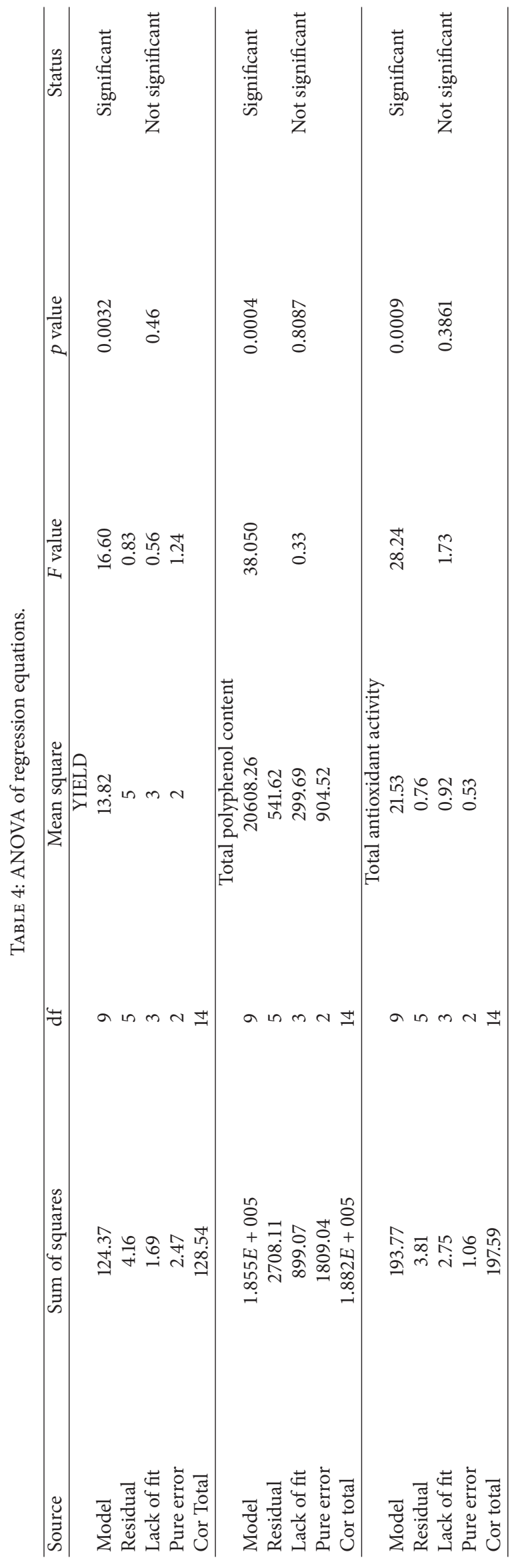


TABLE 5: The $R$ values of the process.

\begin{tabular}{lccc}
\hline Parameters & $R$-squared & Adj. $R$-squared & Predicted $R$-squared \\
\hline Yield & $96.70 \%$ & $90.93 \%$ & $74.61 \%$ \\
Total phenolic content & $98.56 \%$ & $95.97 \%$ & $90.19 \%$ \\
Total antioxidant activity & $98.07 \%$ & $94.60 \%$ & $76.50 \%$ \\
\hline
\end{tabular}

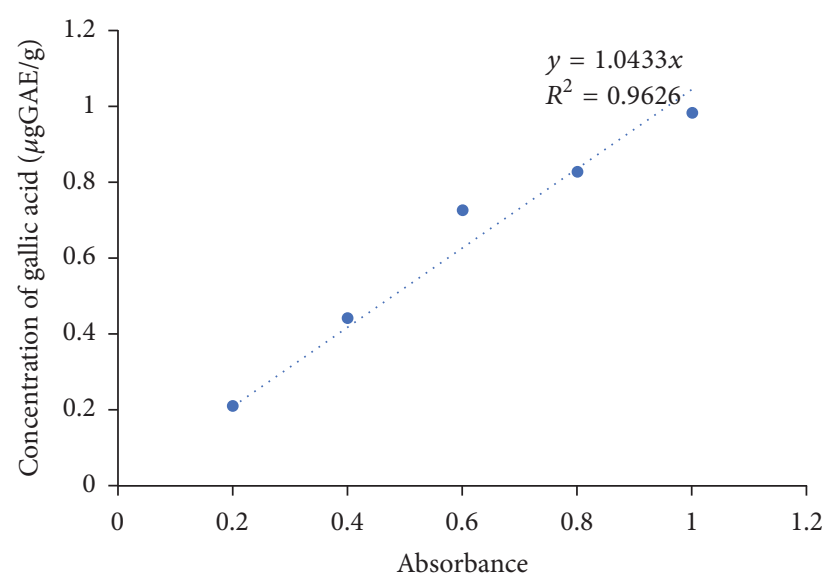

FIGURE 1: Standard curve for determination of phenolic contents.

results for the polyphenol yield, TPC, and TAA, respectively. $R^{2}$ is a measure of the goodness of fit of the model. According to Guan and Yao [20], a model is suitable for navigating the design space if the $R^{2}$ value is at least 0.80 . In the present study, the $R^{2}$ values of all the models for the response results were greater than 0.80 , which suggests goodness of fit of the model. The values of adjusted $R^{2}$ for the response are also high and close to the $R^{2}$ values (Table 5). These values, therefore, support the high significance of the model in predicting the responses for the polyphenol concentrates. The analysis of variance (Table 6) also revealed that the lack of fit was not significant relatively to the pure error, and this further supports the validity of the models for the responses. The regression equations obtained for the independent and dependent variables for the yield $\left(Y_{1}\right)$, TPC $\left(Y_{2}\right)$, and TAA $\left(Y_{3}\right)$ were

$$
\begin{aligned}
Y_{1}= & +23.72+2.37 A-1.15 B+1.80 C+2.11 A B \\
& -0.45 A C+2.20 B C+1.04 A^{2}+0.23 B^{2} \\
& +0.36 C^{2} \\
Y_{2}= & +430.23-50.41 A+6.72 B-0.80 C+16.41 A B \\
& -0.96 A C-127.66 B C+154.03 A^{2}-41.82 B^{2} \\
& -59.01 C^{2} \\
Y_{3}= & 22.22+1.30 A+0.48 B-1.25 C-0.44 A B \\
& +0.80 A C-0.99 B C-5.16 A^{2}-3.68 B^{2} \\
& -2.95 C^{2} .
\end{aligned}
$$

Considering the regression equation for the yield of polyphenol (7), one of the three linear terms (factor $A$ : temperature) has positive effect on the yield of polyphenol, and two interaction terms ( $A B$ : temperature and time; $B C$ : time and ratio of solid to solvent) have positive effects on the yield of polyphenol concentrates. On the TPC of extracts (8), the time of extraction $(B)$ and the interaction of temperature and time $(A B)$ have positive effects. Furthermore, temperature $(A)$ and time $(B)$ as linear factors were also observed to have positive effects even as the interaction between temperature and ratio of material to water $(A C)$ was observed to have positive effects on the TAA as shown in the regression equation (9). The positive effects of the some of the factors on the selected responses showed that the regression model fits the data and was adequate for the prediction of responses.

3.2. Analysis of Surface Plots of the Responses. Threedimensional (3D) response surface plots are representations, which graphically denote the regression equations for the optimization of reaction variables [19]. These surface plots in the present study are shown in Figures 2, 3, and 4. Figure 2(a) showed the interactive effect of the extraction time and the vegetable powder: water ratio on the yield of polyphenol concentrates. The information shown on the figure indicated that higher values of extraction time and the vegetable powder: water ratio resulted in high yield of polyphenol, while lower values of these factors led to decreased yields. This high yield of the extracts could result from higher surface area, which allowed the extracting medium to penetrate the matrix of the material for a longer time [21]. The 3D plot in Figure 2(b) showed interaction of the extraction time and temperature. It was indicated from the plot that increase in the extraction temperature contributed more to an increase 


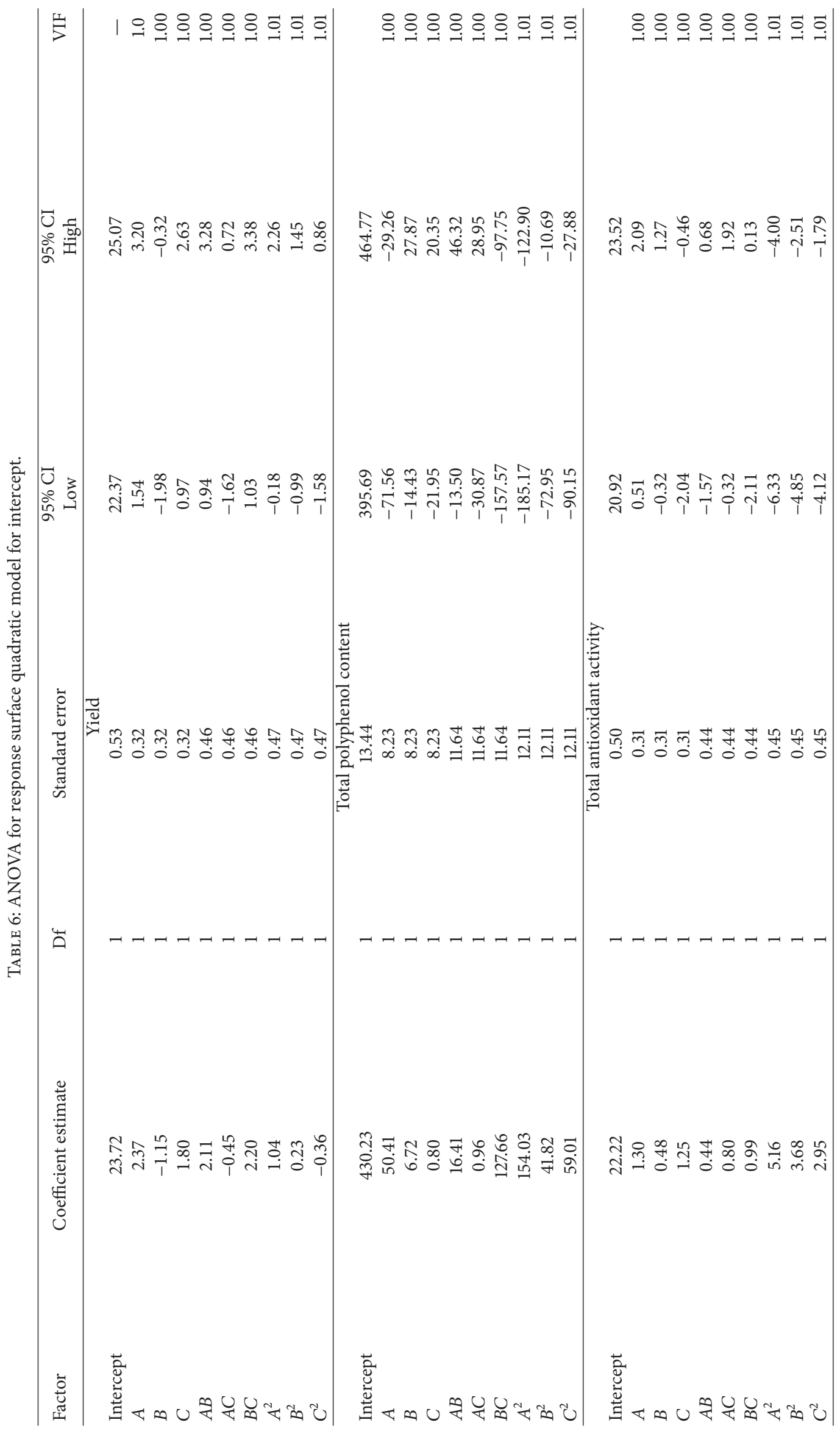




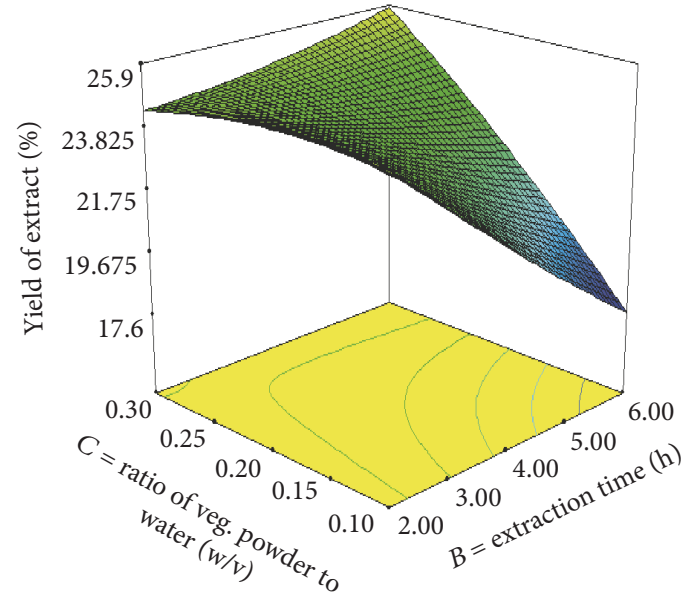

(a)

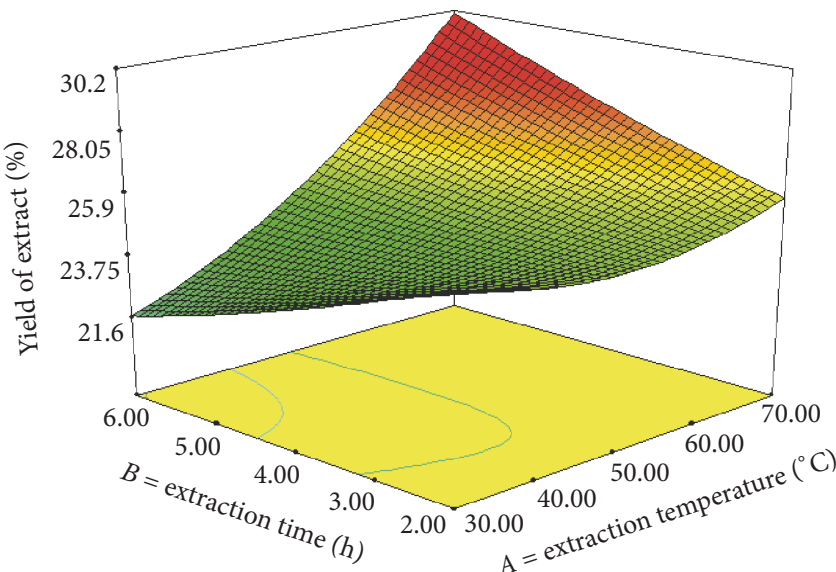

(b)

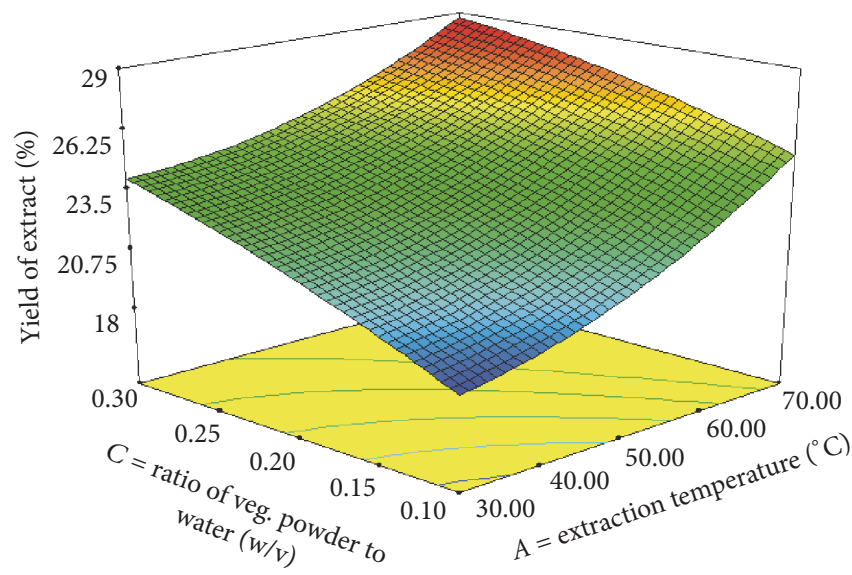

(c)

FIGURE 2: Interaction effects on the yield of Solanum macrocarpon polyphenol concentrates: (a) vegetable powder: water ratio and extraction time; (b) extraction time and temperature; (c) vegetable powder : water ratio and extraction temperature.

in the polyphenol concentrate yields when compared to the extraction time. The same trend was observed in Figure 2(c) in the interactive effect of temperature and the leaf powder: water ratio where there was a progressive increase in polyphenol yield as the two interactive factors increased. This increase in polyphenol concentrate yield might result from the increase in the solubility of the material and wide range of dispersibility of the material in the extracting medium, which were enhanced by increase in the working temperature and material to water ratio with increased extraction time [22].

The nature of the curvatures of three-dimensional surface plots in Figures 3(a), 3(b), and 3(c) showed mutual interactive effects of the extraction temperature, time, and leaf powder: water ratio to extracting solvent on the TPC. In Figure 3(a), the TPC increased when the extraction time was increased from 2 to $4 \mathrm{~h}$ and temperature increased from 30 to $50^{\circ} \mathrm{C}$. Values above these levels of temperature and time resulted in a sharp decrease in the phenolic constituents of the polyphenol concentrates. In Figure 3(b), the interactive effect of temperature and the vegetable powder: water ratio to extracting medium was presented. The trend observed was similar to that in Figure 3(a) where values above $50^{\circ} \mathrm{C}$ led to TPC decreases. The TPC was also observed to decrease as the ratio of the material to extracting medium was raised far above 1:20. The effect of extraction time and vegetable powder: water ratio on TPC is presented in Figure 3(c), which illustrates the positive interactive effect of increased time and material concentration. Figures 3(a), 3(b), and 3(c) represent the effects of selected factors (temperature, time, and leaf powder concentration in extracting medium) on the TAA of the polyphenol concentrates. The nature of curvatures of the surfaces in Figure 4 shows increases in the TAA up to the working temperature of $50^{\circ} \mathrm{C}$, extracting time of $4 \mathrm{~h}$, and leaf powder: water ratio of $1: 20$. Values above these extraction conditions resulted in gradual reduction in the TAA of the polyphenol concentrates.

High extraction temperature has been found to promote higher solute solubility by increasing both solubility and mass transfer rate. In addition, viscosity and surface tension of the extracting media are decreased at higher temperature, which facilitates solute-solvent interactions, thereby improving the extraction rate [9]. However, many phenolic compounds are 


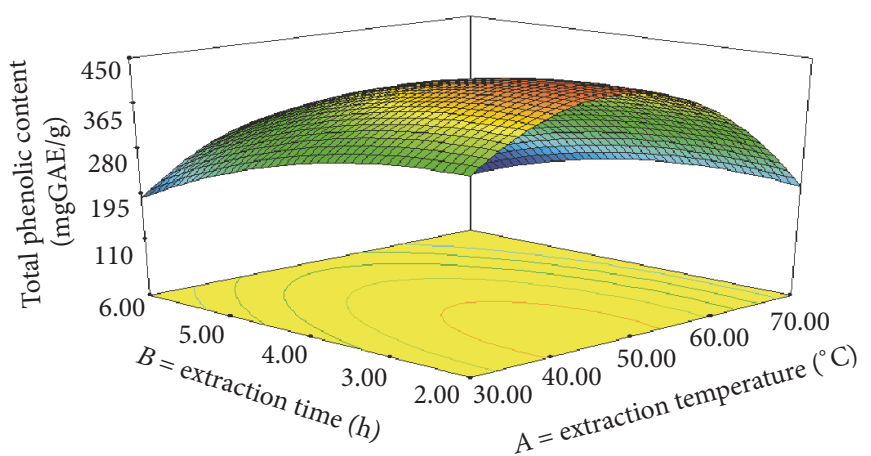

(a)

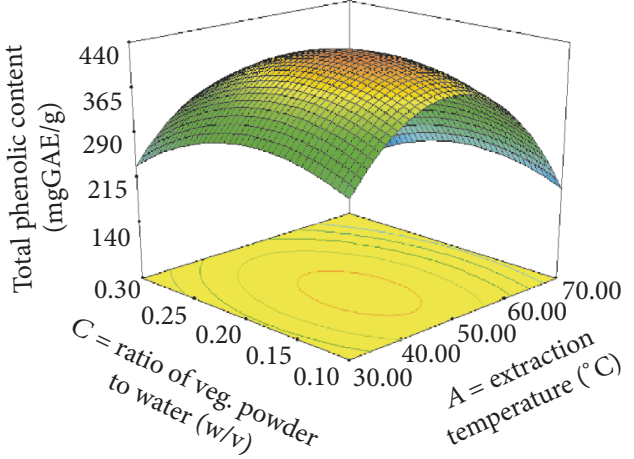

(b)

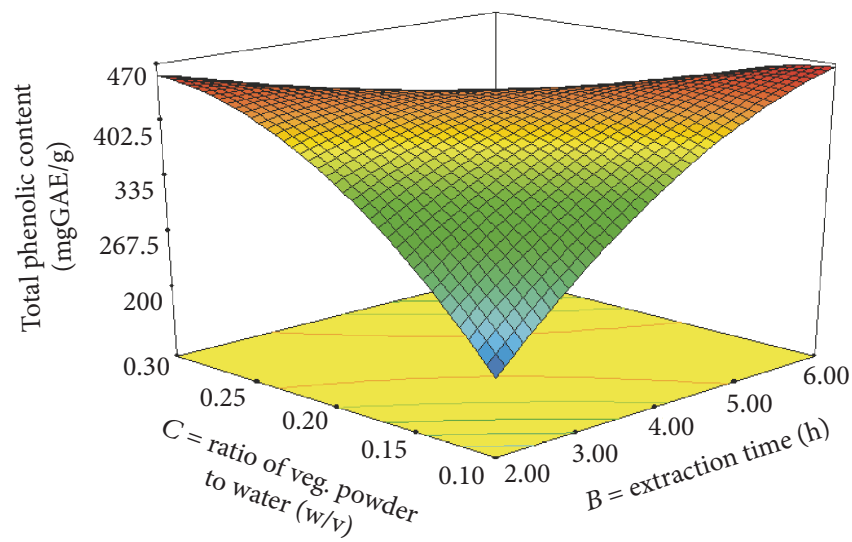

(c)

FIGURE 3: Interaction effects on the total polyphenol content of Solanum macrocarpon polyphenol concentrates: (a) extraction temperature and extraction time; (b) extraction temperature and vegetable powder : water ratio; (c) extraction time and vegetable powder: water ratio.

easily hydrolysed and oxidized. Long extraction times and high temperature increase the tendency of phenolic compounds being oxidized, which decreases the yield of phenolics in the extracts and reduces the antioxidant potency of the phenolic compounds $[9,23]$. This is further supported by the report that indicated high temperatures may cause rapid degradation of polyphenolic compounds $[9,24]$. Therefore, it is important to select efficient extraction conditions in order to maintain stability of phenolic compounds, which has a positive influence on antioxidant properties.

3.3. Process Optimization and Validation. In the determination of the process conditions, the desirability criterion was based on the highest TAA and TPC in addition to a relatively high yield of polyphenol concentrates while keeping the extraction temperature, time, and vegetable powder: solvent ratio at minimum levels. Using the above goals, it was possible to optimize the extraction process. The optimum extraction conditions for the present study were $49.05^{\circ} \mathrm{C}$ temperature, $243 \mathrm{~min}$ extraction time, and vegetable powder: water ratio of $1: 22$. These conditions were selected in order to preserve the antioxidant properties of interest in the polyphenol concentrates. Under these conditions, the optimum values of the polyphenol concentrate yield, TPC, and TAA were $24.94 \%, 421.09 \mathrm{mg} \mathrm{GAE} / \mathrm{g}$, and $23.81 \mathrm{mg} \mathrm{AAE} / \mathrm{g}$, respectively. The optimum value obtained for the total phenolic content in the present study was higher than the values (131 to $230 \mathrm{mg}$ TAE/g) reported by Rafiee et al. [25] for microwave assisted extracts of olive leaves using different organic solvents. Taghvaei et al. [26] produced polyphenol extract from olive leaf using leaf powder to solvent ratio of $1: 10$ with microwave assisted extraction method. This resulted in a lower phenolic content of the extract compared with the optimum value obtained in the present study. The experimental values obtained under these conditions for the yield of polyphenol concentrates, TPC, and TAA were $23.78 \pm 0.22 \%$, $420.00 \pm 1.21 \mathrm{mg} \mathrm{GAE} / \mathrm{g}$, and $23.78 \pm 0.42 \mathrm{mg} \mathrm{AAE} / \mathrm{g}$, respectively. These experimental values are in close agreement with the predicted values, which indicates that the regression equations obtained in the present study were valid in predicting the yield of polyphenol concentrates, its polyphenol contents, and antioxidant activities.

3.4. In Vitro Antioxidant Properties of Polyphenol Concentrate. The antioxidant properties of the polyphenol concentrate obtained from the optimized extraction conditions were determined. The ability of the polyphenol concentrate to scavenge DPPH free radicals was found to be $76.78 \pm 1.11 \%$ while the metal chelating ability was observed to be $80.22 \pm$ $0.97 \%$. Also, the iron reducing capacity of the polyphenol was 


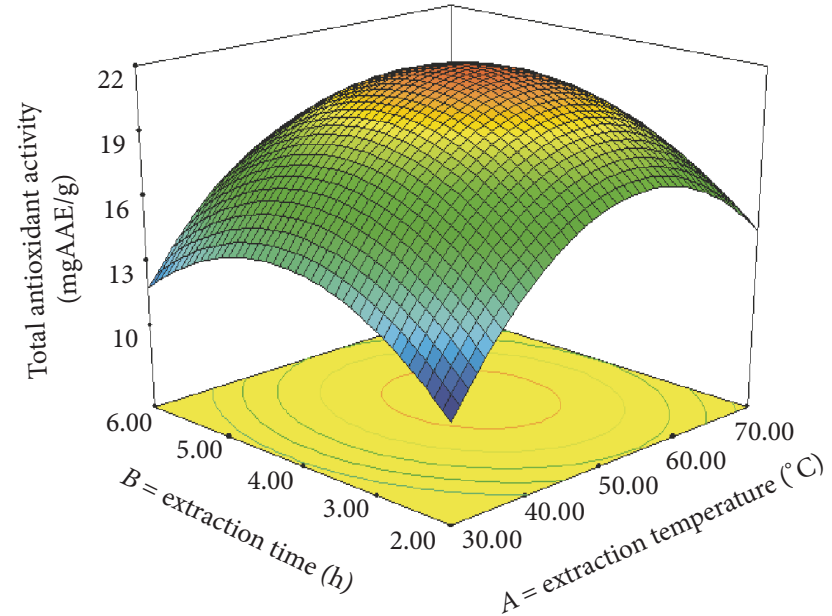

(a)

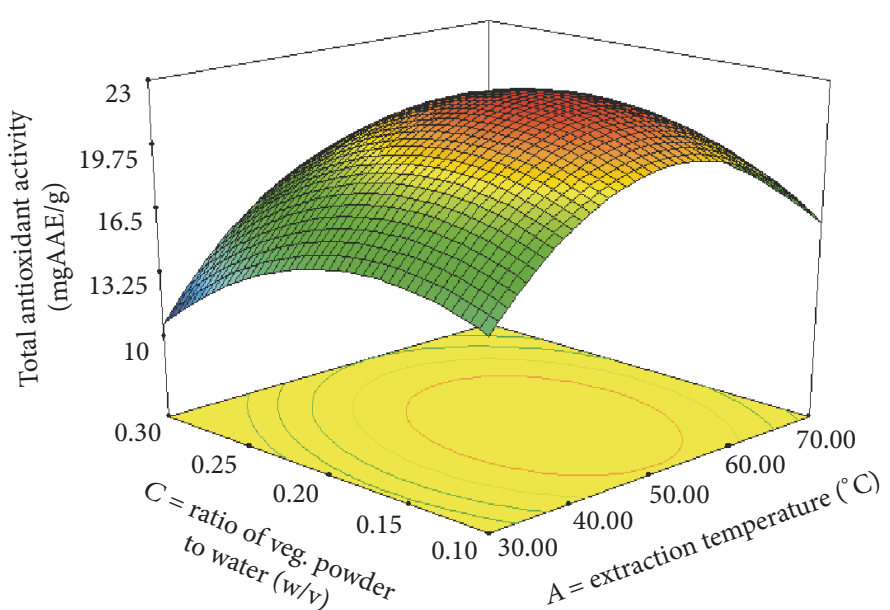

(b)

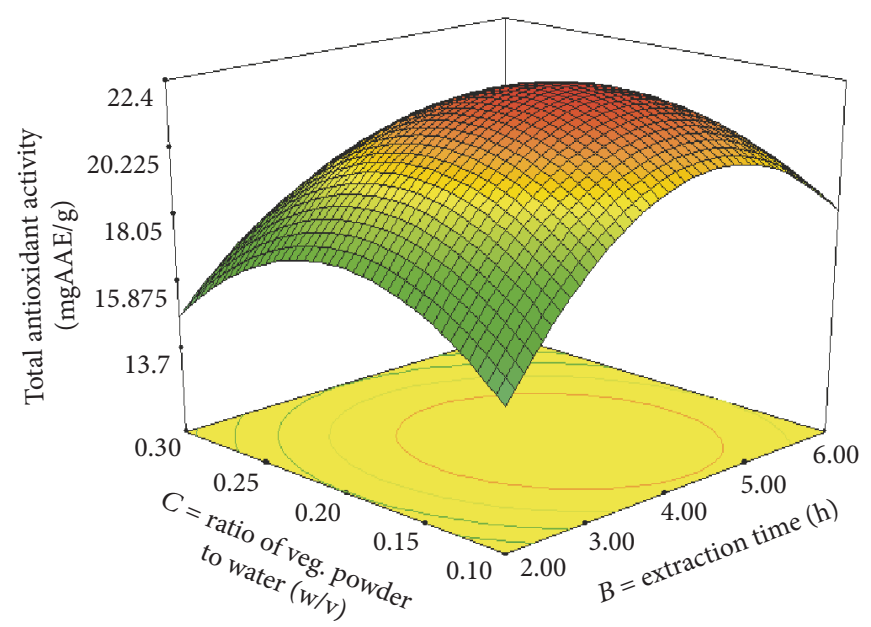

(c)

FIGURE 4: Interaction effects on the total antioxidant activity of Solanum macrocarpon polyphenol concentrates: (a) extraction temperature and extraction time; (b) extraction temperature and vegetable powder: water ratio; (c) extraction time and vegetable powder: water ratio.

$56.46 \pm 1.50 \mathrm{mg} \mathrm{AAE} / \mathrm{g}$. The value obtained for the reducing capacity in this work was higher, compared to the values $(166.45$ to $381.78 \mu \mathrm{g} / \mathrm{ml})$ reported by Rafiee et al. [25] for microwave assisted extracts of olive leaves extracted with different organic solvents. The variation might be related to the difference in the plant origin used in the studies. The antioxidant properties of the polyphenol concentrate were also expressed in terms of $\mathrm{IC}_{50}$ (inhibition concentration that produced 50\% inhibition) in comparison with the standard. Lower $\mathrm{IC}_{50}$ values represent higher potency as an antioxidant [27]. With respect to DPPH scavenging activity, $\mathrm{IC}_{50}$ of the polyphenol concentrate $(1.01 \pm 0.21)$ was comparable with the $0.96 \pm 0.23$ values for ascorbic acid. The $\mathrm{IC}_{50}$ value for metal chelating ability of the polyphenol concentrate was $1.06 \pm 0.18$, which is higher and hence of lower potency when compared to EDTA with a lower value. The DPPH scavenging ability obtained in the present study is higher than the values obtained for S. muricatum fruit extract reported by Herraiz et al. [28]. Somawathi et al. [29] reported lower values of
FRAP (7.65 mg AAE/g) for S. melongena fruit extract when compared with polyphenol concentrate in the present study. The higher antioxidant potency of the $S$. macrocarpon leaves in comparison with Solanum fruits may be due to the high chlorophyll content of the leaves.

\section{Conclusions}

Response surface methodology has been used to optimize the extraction of antioxidant polyphenolic compounds from $S$. macrocarpon leaves. Second polynomial was used and this gave a good description of the experimental data. Combination of experimental variables such as extraction temperature, extraction time, and vegetable powder: water ratio gave optimum conditions for the polyphenol concentrate extraction. The experimental values were found to be in agreement with the predicted values. Investigation into the antioxidant properties of the optimized polyphenol concentrate showed high antioxidant potentials of the phenolic constituents of $S$. 
macrocarpon leaves. This study is, therefore, potentially useful for the development of industrial processes for the large scale aqueous extraction of polyphenol concentrates from $S$. macrocarpon leaves.

\section{Additional Points}

Practical Applications. The study investigated the optimum conditions for the production of polyphenol concentrates from the dried leaf of Solanum macrocarpon, using surface response methodology. The study predicted the optimum conditions for the production of polyphenol concentrates from the leaf of Solanum macrocarpon which showed high phenolic content. In vitro antioxidants of the polyphenol extracted with the optimum conditions showed high antioxidative activities. Therefore, polyphenol concentrates with high phenolic contents and antioxidative properties can be obtained from dried leaf of Solanum macrocarpon using the optimized conditions.

\section{Conflicts of Interest}

The authors declare that there are no conflicts of interest regarding the publication of this paper. The funding of the project did not generate any conflicts of interest in the publication of the work.

\section{Acknowledgments}

Funding for this work was provided by IDRC (International Development Research Centre) and the Global Affairs Canada/Canadian International Food Security Research Fund (DFATD/CIFSRF) through Project 107983 on synergizing indigenous vegetables and fertilizer microdosing innovations among West African farmers.

\section{References}

[1] G. Oboh, M. M. Ekperigin, and M. I. Kazeem, "Nutritional and haemolytic properties of eggplants (Solanum macrocarpon) leaves," Journal of Food Composition and Analysis, vol. 18, no. 2-3, pp. 153-160, 2005.

[2] M. K. Osei, B. Banful, C. K. Osei, and M. O. Oluoch, "Characterization of african eggplant for morphological characteristics," Journal of Agricultural and Science Technology, vol. 4, no. 3, pp. 33-37, 2010.

[3] S. O. Bello, B. Y. Muhammad, K. S. Gammaniel et al., "Preliminary evaluation of the toxicity and some pharmacological properties of the aqueous crude extract of solanum melongena," Research Journal of Agriculture, Biology and Science, vol. 1, no. 1, pp. 1-9, 2005.

[4] C. M. Messiaen, The Tropical Vegetable Garden, Macmillan Press Limited, London and Basingstoke, 1992.

[5] G. Komlaga, G. H. Sam, R. A. Dickson, M. L. K. Mensah, and T. C. Fleischer, "Pharmacognostic studies and antioxidant properties of the leaves of Solanum macrocarpon," Journal of Pharmaceutical Sciences and Research, vol. 6, no. 1, pp. 1-4, 2014.
[6] A. A. Odetola, Y. O. Iranloye, and O. Akinloye, "Hypolipidaemic potentials of solanum melongena and solanum gilo on hypercholesterolemic rabbits," Pakistan Journal Nutrition, vol. 3, no. 3, pp. 180-187, 2004.

[7] M.-C. Sánchez-Mata, W. E. Yokoyama, Y.-J. Hong, and J. Prohens, " $\alpha$-Solasonine and $\alpha$-solamargine contents of gboma (solanum macrocarpon 1.) and scarlet (solanum aethiopicum 1.) eggplants," Journal of Agricultural and Food Chemistry, vol. 58, no. 9, pp. 5502-5508, 2010.

[8] A. Singh, A. Kuila, G. Yadav, and R. Banerjee, "Process optimization for the extraction of polyphenols from okara," ood Technology and Biotechnology, vol. 49, no. 3, pp. 322-328, 2011.

[9] J. Dai and R. J. Mumper, "Plant phenolics: extraction, analysis and their antioxidant and anticancer properties," Molecules, vol. 15, no. 10, pp. 7313-7352, 2010.

[10] B. J. Xu and S. K. C. Chang, "A comparative study on phenolic profiles and antioxidant activities of legumes as affected by extraction solvents," Journal of Food Science, vol. 72, no. 2, pp. S159-S166, 2007.

[11] D. Baş and I. H. Boyaci, "Modeling and optimization I: usability of response surface methodology," Journal of Food Engineering, vol. 78, no. 3, pp. 836-845, 2007.

[12] M. Sarfarazi, S. M. Jafari, and G. Rajabzadeh, "Extraction Optimization of Saffron Nutraceuticals Through Response Surface Methodology," Food Analytical Methods, vol. 8, no. 9, pp. 22732285, 2015.

[13] V. L. Singleton and J. A. Rossi, "Colorimetry of total phenolics with phosphomolybdic phosphotungstic acid reagents," American Journal of Enology and Viticulture, vol. 16, no. 3, pp. 144-158, 1999, ISSN 002-9254.

[14] P. Prieto, M. Pineda, and M. Aguilar, "Spectrophotometric quantitation of antioxidant capacity through the formation of a phosphomolybdenum complex: specific application to the determination of vitamin E," Analytical Biochemistry, vol. 269, no. 2, pp. 337-341, 1999.

[15] T. L. Pownall, C. C. Udenigwe, and R. E. Aluko, "Amino acid composition and antioxidant properties of pea seed (Pisum sativum L.) Enzymatic protein hydrolysate fractions," Journal of Agricultural and Food Chemistry, vol. 58, no. 8, pp. 4712-4718, 2010.

[16] I. F. F. Benzie and J. J. Strain, "The ferric reducing ability of plasma (FRAP) as a measure of 'antioxidant power': the FRAP assay," Analytical Biochemistry, vol. 239, no. 1, pp. 70-76, 1996.

[17] N. Singh and P. S. Rajini, "Free radical scavenging activity of an aqueous extract of potato peel," Food Chemistry, vol. 85, no. 4, pp. 611-616, 2004.

[18] L. Quanhong and F. Caili, "Application of response surface methodology for extraction optimization of germinant pumpkin seeds protein," Food Chemistry, vol. 92, no. 4, pp. 701-706, 2005.

[19] E. Betiku and T. F. Adepoju, "Methanolysis optimization of sesame (Sesamum indicum) oil to biodiesel and fuel quality characterization," International Journal of Energy and Environmental Engineering, vol. 4, no. 1, pp. 1-8, 2013.

[20] X. Guan and H. Yao, "Optimization of Viscozyme L-assisted extraction of oat bran protein using response surface methodology," Food Chemistry, vol. 106, no. 1, pp. 345-351, 2008.

[21] D. De Faveri, B. Aliakbarian, M. Avogadro, P. Perego, and A. Converti, "Improvement of olive oil phenolics content by means of enzyme formulations: Effect of different enzyme activities and levels," Biochemical Engineering Journal, vol. 41, no. 2, pp. 149-156, 2008. 
[22] T. Juntachote, E. Berghofer, F. Bauer, and S. Siebenhandl, “The application of response surface methodology to the production of phenolic extracts of lemon grass, galangal, holy basil and rosemary," International Journal of Food Science \& Technology, vol. 41, no. 2, pp. 121-133, 2006.

[23] R. L. Jackman, R. Y. Yada, M. A. Tung, and R. A. Speers, "Anthocyanins as food colorants-a review," Journal of Food Biochemistry, vol. 11, pp. 201-247, 1987.

[24] L. Havlikova and K. Mikova, "Heat stability of anthocyanins," $Z$. Lebensm.-Unters. Forsch, vol. 181, pp. 427-432, 1985.

[25] Z. Rafiee, S. M. Jafari, M. Alami, and M. Khomeiri, "Antioxidant effect of microwave-assisted extracts of olive leaves on sunflower oil," Journal of Agricultural Science and Technology, vol. 14, pp. 1497-1509, 2012.

[26] M. Taghvaei, S. M. Jafari, A. S. Mahoonak et al., "The effect of natural antioxidants extracted from plant and animal resources on the oxidative stability of soybean oil," LWT-Food Science and Technology, vol. 56, no. 1, pp. 124-130, 2014.

[27] S. M. Al-Reza, V. K. Bajpai, and S. C. Kang, "Antioxidant and antilisterial effect of seed essential oil and organic extracts from Zizyphus jujuba," Food and Chemical Toxicology, vol. 47, no. 9, pp. 2374-2380, 2009.

[28] F. J. Herraiz, D. Villaño, M. Plazas et al., "Phenolic profile and biological activities of the pepino (Solanum muricatum) fruit and itswild relative S. caripense," International Journal of Molecular Sciences, vol. 17, no. 3, article no. 394, 2016.

[29] K. M. Somawathi, V. Rizliya, D. G. N. G. Wijesinghe, and W. M. T. Madhujith, "Antioxidant activity and total phenolic content of different skin coloured brinjal (solanum melongena," Tropical Agricultural Research, vol. 26, no. 1, pp. 152-161, 2014. 

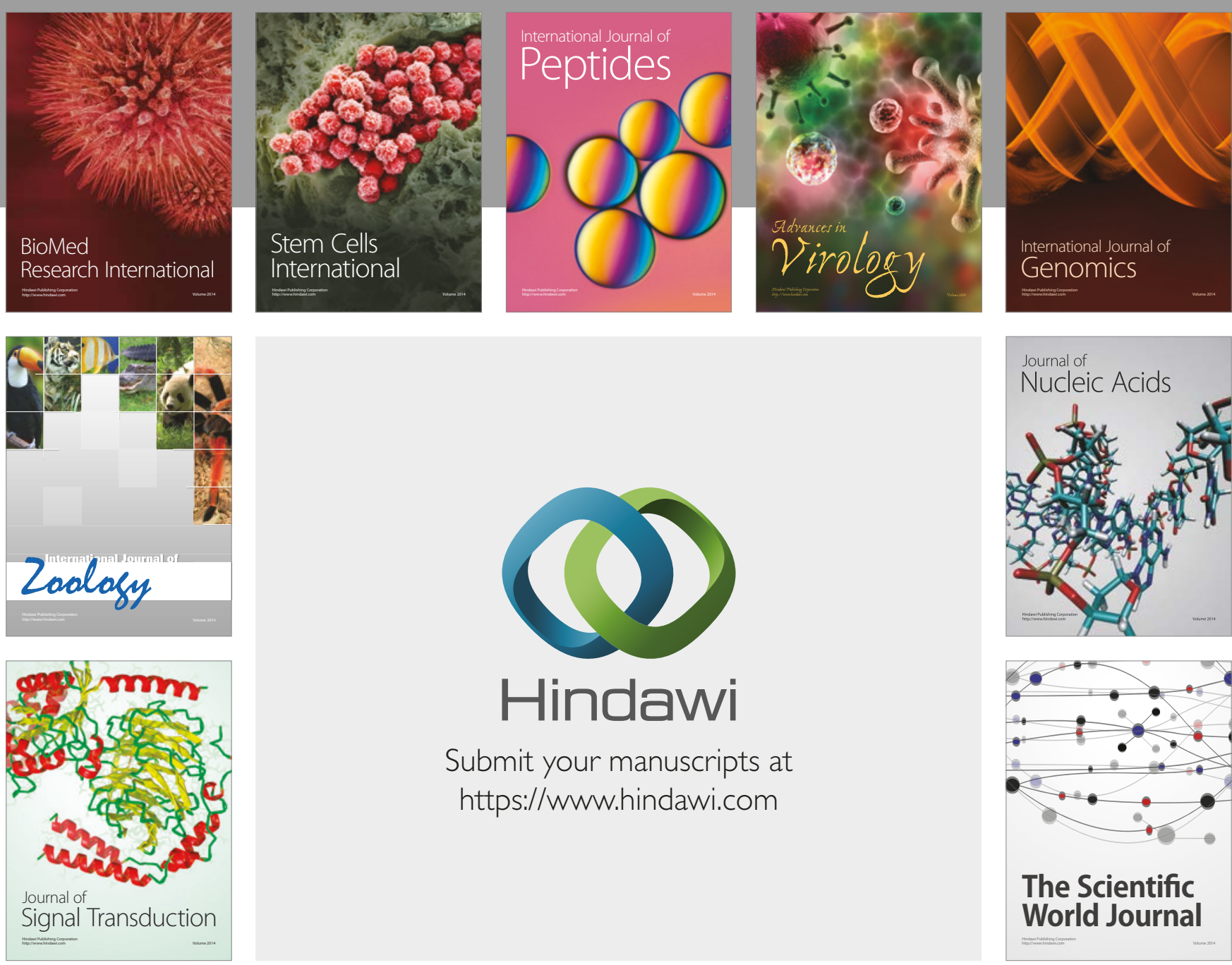

Submit your manuscripts at

https://www.hindawi.com
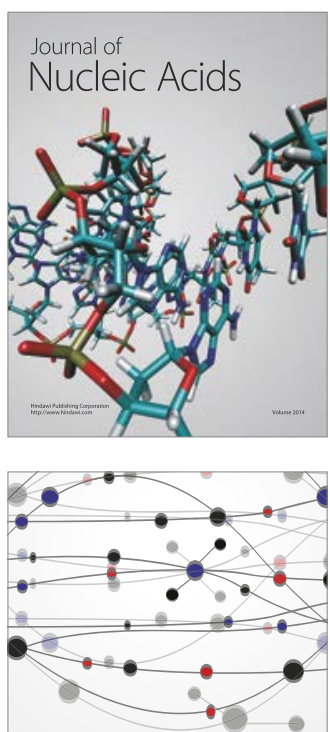

The Scientific World Journal

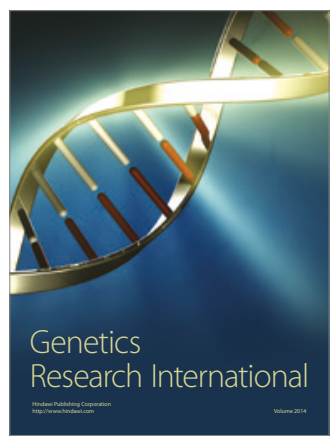

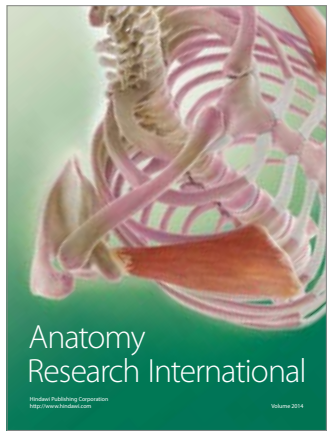

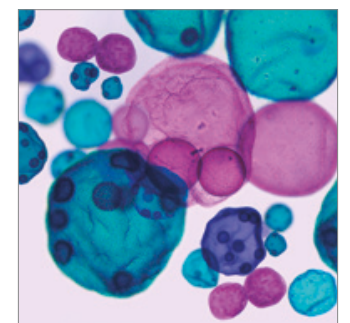

International Journal of Microbiology
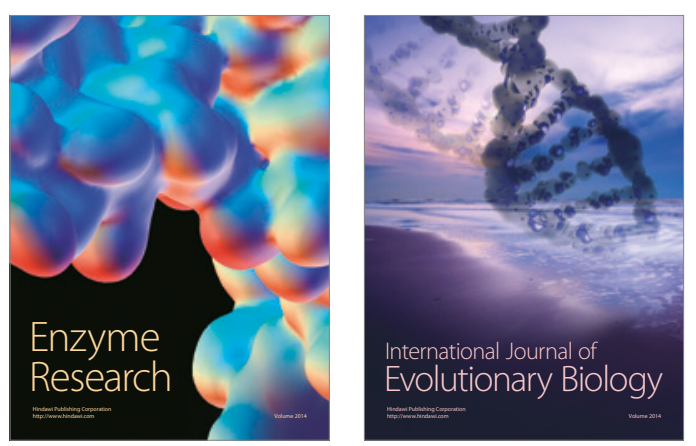
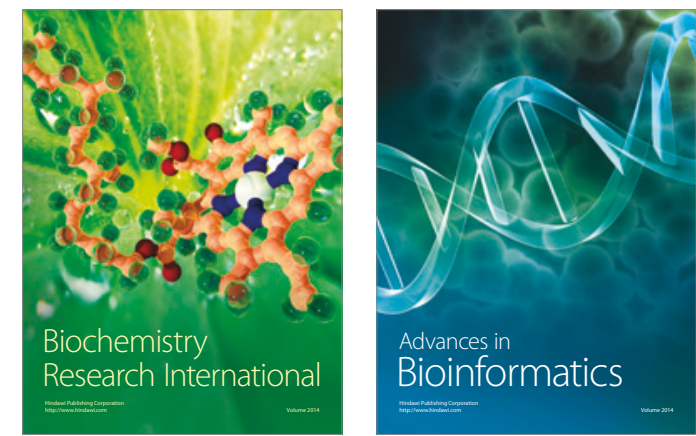

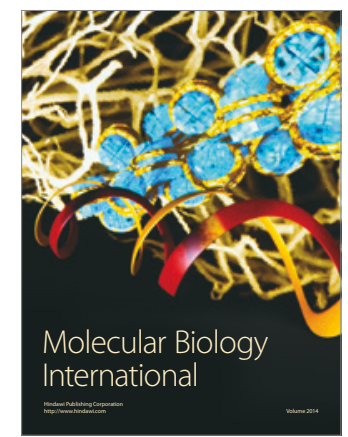

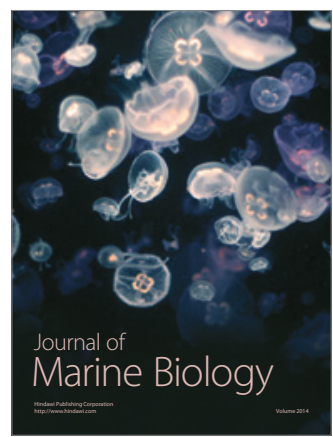

